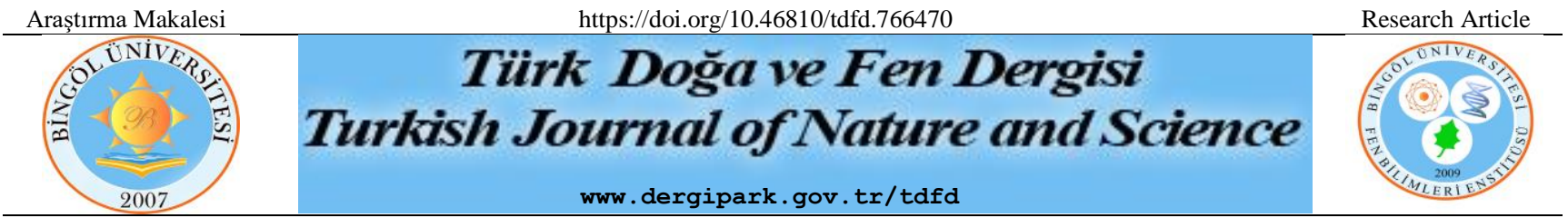

\title{
$\gamma$ CuTi Nanotellerinin Germe Oranı ve Boyuta Bağlı Mekanik Davranışı
}

\author{
Vildan GÜDER $^{1 *}$, Murat ÇELTEK ${ }^{2}$ \\ ${ }^{1}$ Trakya Üniversitesi, Fen Fakültesi, Fizik Bölümü, Edirne, Türkiye \\ ${ }^{2}$ Trakya Üniversitesi, Eğitim Fakültesi, Matematik ve Fen Bilimleri Eğitimi Bölümü, Edirne, Türkiye \\ Vildan GÜDER ORCID No: 0000-0002-8673-2127 \\ Murat ÇELTEK ORCID No: 0000-0001-7737-0411
}

*Sorumlu yazar: vildanguder@trakya.edu.tr

(Alınış: 09.08.2020, Kabul: 10.10.2020, Online Yayınlanma: 30.12.2020)

Anahtar
Kelimeler
$\gamma$ CuTi Nanotelleri,
Moleküler Dinamik
Benzetimleri,
Boyut Etkisi,
Germe
Deformasyonu,
Elastisite
Modülü

Anahtar

Kelimeler

Moleküler Dinan

Benzetimleri,

Boyut Etkisi,

Deformasyonu,

Modülü
Öz: Bu çalışma, farklı boyutlarda $\gamma \mathrm{CuTi}$ (B11) kristal nanotellerinin [001] yönündeki esneklikkırılma mekanizmasını ve deformasyonunu gözlemek için ayrıntılı bir analiz sunmaktadır. Germe oranı ve boyut gibi değişkenlerin nanotelin mekanik özellikleri üzerine etkileri etkileşmelerin gömülü atom potansiyeli ile tanımlandığı moleküler dinamik benzetimleri ile incelenmiştir. Uygulanan diş değişkenlerin $\gamma \mathrm{CuTi}$ nanotellerinin elastik ve plastik deformasyonları üzerindeki etkileri iki temel başlık altında özetlenmiştir. Nanotelin elastik tepkisinin yüksek germe oranı ve küçük boyut ile arttığı gözlenmiştir. Germe oranı etkisi ile Elastisite Modülünün karakterizasyonu arasında belirli bir bağlantı gözlenmezken, nanotel boyutunun istenen dayanıklılık mekanizmasını belirlemede daha etkin role sahip olduğu görülmüştür. Diğer yandan, düşük germe oranı ve küçük boyutun $\gamma \mathrm{CuTi}$ nanotellerin kırılma dayanımını ve esnekliğini azalttığı izlenmiştir.

\section{Strain Rate and Size Dependent Mechanical Behavior of $\gamma \mathrm{CuTi}$ Nanowires}

Keywords
$\gamma \mathrm{CuTi}$
Nanowires,
Molecular
Dynamics
Simulations,
Size Effect,
Tensile
Deformation,
Elasticity
Modulus

\begin{abstract}
This study is a comprehensive analysis to observe the elasticity-fracture mechanism and the deformation in the direction of [001] of different size of $\gamma \mathrm{CuTi}$ (B11) nanowires. The strain rate and size related effects on the mechanical properties of nanowires are investigated the molecular dynamic simulation in which all interactions were defined by the embedded atom potentials. The effects of these external variables on elastic and plastic deformations of $\gamma \mathrm{CuTi}$ nanowires are summarized in two schemes. It is observed that the elastic response of nanowire increases with higher strain rate and smaller size. While no specific relation was observed between the effect of strain rate and the characterization of the Elasticity Modulus, the size of nanowire has more effective role in the engineering of the strength mechanism. On the other hand, the lower strain rate and smaller size reduce the fracture and ductility of $\gamma \mathrm{CuTi}$ nanowires.
\end{abstract}

\section{GIRIŞ}

Yeni elektromekanik cihazların tasarımı, sistemin deformasyon mekanizmasının ve ilgili mekanik özelliklerinin iyi anlaşılabilmesinden geçmektedir. Bu cihazların ölçeği mikro ve nanometre boyutlarına düştüğünde, nanotellerin bulk (hacimsel) sistemlere kıyasla eşsiz mekanik ve geçiş özelliklerine sahip olmaları mühendislerin ve bilim insanlarının büyük ilgisini çekmiş ve doğal olarak nanoteller malzeme fiziğinin ilgi çekici alanlarından biri olmuştur [1]. Nanoteller nano-elektronik, nano-optoelektronik ve nano-mekaniğin potansiyel uygulamalarında güçlü ve kararlı olmaları [2,3] ile termal [4], mekanik [5], elektronik [6] ve optik özellikleri [7] nedeniyle yaygın olarak kullanılmaktadır. Son zamanlarda rapor edilen çalışmalar nanotellerin test edilmesi sırasında gözlenen süperelastisite, süperplastisite, geri kazanılabilir plastisite, esneklik dışı ve ultra yüksek mukavemet gibi eşsiz özelliklerin geleneksel bulk materyallerde gözlemlenmediğini göstermiştir [8]. Bu sonuçlar, her ne kadar yoğun çalışma icra edilmiş olsa da, karmaşık yüzey morfolojisi ve küçük boyuta sahip nanotellerde uygulanan deneysel yöntemlerin bu malzemeler hakkında sunduğu bilgilerin sınırlılığg nedenleriyle diş değişkenler altındaki deformasyon mekanizmasının detaylı incelenmesinin gerekliliğini ortaya koyar [9]. 
Germe oranı ve boyut gibi farklı dıș koșullar altında germe koşullarının kontrol edilmesine izin veren MD benzetimleri, nanotellerin atomik ölçekteki mekanik deformasyonunun incelenmesi konusunda büyük avantajlara sahiptir. Liang ve ark. [10] gömülü atom metod (GAM) potansiyeli ile MD benzetimi kullanarak $\mathrm{Cu}$ nanotellerin [001], [110] ve [111] kristalografik yönleri boyunca esnekliğini incelemişler ve ilginç sonuçlar elde etmişlerdir. Bir başka çalışmada $\mathrm{Cu}$ nanotellerinin çekme davranıșı üzerindeki gerilme oranının etkisi MD benzetim ile incelenmiş ve akma geriliminin, düşük germe oranlarından etkilenmediği, orta germe oranlarında arttığ 1 ve çok daha yüksek germe oranlarında azaldığı izlenmiștir [11]. Chang ve ark. [12] $3 \mathrm{~nm}$ ile $20 \mathrm{~nm}$ arasında değişen boyuta sahip Ti nanotellerinin [0001] yönünde ve yüksek germe oranı altında boyuta bağlı deformasyon mekanizmasını araștırmıșlar ve yüksek germe oranı altında deformasyon ikizlenmesi ve plastik bölgede hcp'den fcc'ye faz dönüşümü gerçekleştiğini gözlemlemişlerdir. Ti nanotellerinin germe deformasyonu üzerinde germe oranı etkisini MD ile araştıran çalışmada $0.01 \mathrm{ps}^{-1}$ 'nin üzerindeki germe oranlarında nanotelin süperplastik davranışına neden olan düzensiz bir yapıya (amorf) geçiş yaptığı gözlemlenmiştir [13]. Ajori ve ark. [14] raporladıkları MD çalışmasında, metalik cam nanokompozitlerin burulma davranışının $\mathrm{Cu}$ nanotel ve C nanotüp katkılamasıyla karakterize edilebildiğini göstermişlerdir. $\mathrm{Hem} \mathrm{Cu}$ hem de $\mathrm{Ti}$ nanotellerinde gözlenen bu birbirinden ilginç sonuçlar her iki elementin karıştırılması ile ortaya çıkan CuTi alaşımlarına ve nanotellerine olan ilgiyi de artırmıştır. Önceki yıllarda $\mathrm{CuTi}$ alaşımlarının hem temel metalürjisi hem de pratik uygulamaları üzerine ilginç sonuçlar sunan birçok araştırma gerçekleştirilmiştir [15-18]. Tetragonal CuTi intermetalik bileşenlerinin ilk prensip hesaplamaları ile yapısal, elastik ve termodinamik özelliklerinin incelendiği çalışmada örgü sabiti, elastik sabiti, bulk, kayma ve young modülü gibi özellikleri deneysel datalar ile tutarlı şekilde elde edilmiştir [19]. Chen ve ark. [20], $\mathrm{CuTi}$ intermetaliklerinin yapısal özelliklerini, faz kararlılıklarını, anizotropik elastik özelliklerini ve elektronik yapılarını yoğunluk fonksiyonel teorisine dayanan ilk prensip yaklaşımını kullanarak sistematik olarak araștırmışlardır. Vauth ve Mayr [21] MD benzetimleri kullanarak cam geçiş sıcaklığının altındaki metalik cam ince filmlerde atomik dinamikler üzerine araştırmalar gerçekleştirmişlerdir. Dalgic ve Celtek [22] $\gamma \mathrm{CuTi}$ kristalinin erime sürecini ve sıvı $\mathrm{CuTi}$ alaşımının soğutma sürecindeki cam oluşum, kristalizasyon ve atomik yapısının gelişimini sıkı bağlı (Tigh-Binding) çok cisim potansiyeli kullanarak MD benzetimleri ile incelemişlerdir. Son zamanlarda ise, Rogachev ve ark. [23] CuTi metalik camındaki devitrifikasyon ve kristalleşme süreçlerini atomik benzetim yöntemlerini kullanarak araştırmışlardır. Semboshi ve Takasugi [18] hidrojen atmosferinde yaşlandırılarak yüksek mukavemetli ve yüksek iletkenliğe sahip CuTi alaşımlı bir tel modeli sunmuşlardır. Dahası, sensör uygulamaları için nano mimarili $\mathrm{Ti}_{\mathrm{x}} \mathrm{Cu}_{\mathrm{y}}$ ince filmlerin piezo dirençli yanitı [24], katmanlı $\mathrm{Ti} / \mathrm{Cu} / \mathrm{Ti}$ kaplı malzemelerin mekanik tepkisi ve kırılmasında intermetalik bileşenlerin gelişimi [25] ve hızlı katılaşma sırasında sıvı metalik
$\mathrm{Ti}_{62} \mathrm{Cu}_{38}$ alaşımının yapı oluşumu üzerindeki yüksek basıncın etkileri ile ilgili çalışmalar gerçekleștirilmiștir [26]. Yukarıda bahsedilen çalışmaların ekseni CuTi sistemlerinin atomik yapısı, cam oluşumu ve kristalizasyon süreçleri üzerine yoğunlaşmışken mevcut bilgi ve literatür araştırmalarımız $\gamma \mathrm{CuTi}$ nanotellerinin germe altında mekanik özellikleri üzerine herhangi bir araştırmanın yapılmadığ 1 yönündedir. Çalışmamızda, literatürde gözlediğimiz bu eksiklikten yola çıkarak $\gamma \mathrm{CuTi}$ nanotellerinin deformasyon mekanizmasını iyi anlayabilmek için, nanotellerin mekanik özelliklerinin germe oranı ve boyuta bağlı değişimi GAM potansiyeli ile birlikte MD benzetim yöntemi kullanılarak ayrıntılı bir șekilde inceledik. $\gamma \mathrm{CuTi}$ nanotelinin tek eksenli germe deformasyonları, on farklı boyutta $(1,2 \mathrm{~nm}, 2,2$ $\mathrm{nm}, 3,4 \mathrm{~nm}, 4,3 \mathrm{~nm}, 5,2 \mathrm{~nm}, 6,2 \mathrm{~nm}, 7,7 \mathrm{~nm}, 9,3 \mathrm{~nm}$, $10,8 \mathrm{~nm}$ ve $12,4 \mathrm{~nm})$ ve beş farklı germe oranı altında $\left(3 \times 10^{-3} \mathrm{ps}^{-1}, 2 \times 10^{-3} \mathrm{ps}^{-1}, 1 \times 10^{-3} \mathrm{ps}^{-1}, 5 \times 10^{-4} \mathrm{ps}^{-1} \mathrm{ve} 1 \times 10^{-4}\right.$ $\mathrm{ps}^{-1}$ ) gerçekleştirilmiştir. Tüm sistemlerde akma ve kırılma meydana getirebilmek için \% 100 germe uygulanmıştır. Elde edilen sonuçlar, yüzey geriliminin nanotellerin mekanik özelliklerindeki radikal değișiklikten sorumlu olduğunu ve yüzey etkisinin 1,2 $\mathrm{nm}$ boyutlu nanotelde en etkili olmak üzere $4,3 \mathrm{~nm}$ 'den küçük boyutlu nanoteller için daha belirgin hale geldiğini ortaya koymaktadır. $\mathrm{Bu}$ çalışma, boyutun $\gamma \mathrm{CuTi}$ nanotellerinin istenen mekanik özelliklerinin mühendislik uygulamasında germe oranından daha etkili olduğunu göstermiştir.

\section{MATERYAL VE METOT}

$\gamma \mathrm{CuTi}$ nanotellerin mekanik özellikleri üzerine boyut ve germe oranı gibi iki dış değişkenin etkilerini araştırmak için Large-Scale Atomic-molecular Massively Parallel (LAMMPS) [27] açık kaynak kodu kullanılmıștır. Bütün benzetimlerde $\mathrm{Cu}-\mathrm{Cu}, \mathrm{Cu}-\mathrm{Ti}$ ve Ti-Ti atom çiftleri arasındaki etkileşmeleri tanımlamak için daha önce metalik sistemlerin kırılma, kusur ve tane sınırları gibi özelliklerini açıklamakta $[23,28-30]$ başarılı sonuçlar verdiği rapor edilen Zhou ve ark. [31] tarafindan geliştirilen GAM potansiyeli kullanılmıştır. GAM potansiyelinin genel formu eşitlik 1. şeklinde ifade edilebilir:

$$
E=\frac{1}{2} \sum_{i, j, i \neq j} \phi_{i j}\left(r_{i j}\right)+\sum_{i} F_{i}\left(\rho_{i}\right)
$$

burada $\phi_{i j}$ ve $r_{i j}$ sırasıyla $i$ ve $j$ atomları arasındaki çiftler potansiyeli ve uzaklığ temsil eder. $F_{i}$, elektron yoğunluğu $\rho_{i}$ 'nin

$$
\rho_{i}=\sum_{i, j, i \neq j} f_{j}\left(r_{i j}\right)
$$

eșitlik 2. ile verildiği yerel bölgeye $i$ atomun gömülmesi ile ilişkili gömme enerjisidir. İkili sistemler için model saf elementlerin elektron yoğunluğunun $\left(\rho_{C u}(r), \rho_{T i}(r)\right)$, gömme enerjisinin $\left(F_{C u}\left(\rho_{i}\right), F_{T i}\left(\rho_{i}\right)\right)$ ve kendi türü içindeki etkileşme potansiyelinin $\left(\phi_{C u, C u}(r), \phi_{T i, T i}(r)\right)$ ifadesi ile ikili 
etkileşme potansiyelinin tanımını $\left(\phi_{C u, T i}(r)\right)$ temsil eden yedi fonksiyon içerir. Aynı tipteki atomlar arasındaki çiftler potansiyelinin fonksiyonel formu eşitlik 3. şeklinde verilebilir;

$$
\begin{aligned}
\phi(r)=\frac{A \exp \left\{-\alpha\left(\frac{r}{r_{e}}-1\right)\right\}}{1+\left(\frac{r}{r_{e}}-\kappa\right)^{20}} \\
-\frac{B \exp \left\{-\beta\left(\frac{r}{r_{e}}-1\right)\right\}}{1+\left(\frac{r}{r_{e}}-\lambda\right)^{20}}
\end{aligned}
$$

burada $A, B, \quad \alpha$ ve $\beta$ dört farklı ayarlanabilir parametrelerdir. $r_{e}$ en yakın komşu arasındaki denge mesafesidir. $\kappa$ ve $\lambda$ ise kesme parametreleridir [37]. Eşitlik 4.'de verilen elektron yoğunluğu fonksiyonu eşitlik 3.'de verilen çiftler potansiyelin ikinci kısmına çok benzerdir ve tek fark $B$ parametresi yerine $f_{e}$ kullanılmıştır:

$$
\rho(r)=\frac{f_{e} \exp \left\{-\beta\left(\frac{r}{r_{e}}-1\right)\right\}}{1+\left(\frac{r}{r_{e}}-\lambda\right)^{20}}
$$

$\mathrm{Cu}$ ve Ti türleri arasındaki çiftler potansiyel formu eşitlik 5.

$$
\phi_{C u, T i}(r)=\frac{1}{2}\left[\frac{\rho_{C u}}{\rho_{T i}} \phi_{C u, C u}(r)+\frac{\rho_{T i}}{\rho_{C u}} \phi_{T i, T i}(r)\right]
$$

şeklinde verilir. Gömülü enerji fonksiyonu üç farklı elektron yoğunluğu aralığında fit edilerek

$$
\begin{aligned}
& F(\rho) \\
& =\left\{\begin{array}{l}
\sum_{i=0}^{3} F_{n i}\left(\frac{\rho}{\rho_{n}}-1\right)^{i}, \quad \rho<\rho_{n}, \quad \rho_{n}=0.85 \rho_{e}, \\
\sum_{i=0}^{3} F_{i}\left(\frac{\rho}{\rho_{e}}-1\right)^{i}, \quad \rho_{n} \leq \rho<\rho_{0}, \quad \rho_{0}=1.15 \rho_{e}, \\
F_{e}\left[1-\ln \left(\frac{\rho}{\rho_{s}}\right)^{\eta}\right]\left(\frac{\rho}{\rho_{s}}\right)^{\eta}, \quad \rho_{0} \leq \rho
\end{array}\right.
\end{aligned}
$$

eşitlik 6. şeklinde parçalı fonksiyonla ifade edilir. Saf $\mathrm{Cu}$ ve Ti için GAM potansiyel parametreleri [31] Tablo 1'de verilmektedir. Potansiyel formu ve parametrizasyon yöntemi ile ilgili daha ayrıntılı bilgi için [28,30-32] kaynaklarına bakınız.

$\gamma \mathrm{CuTi}$ nanotelin atomik ideal B11 kristal yapısı (P4/nmm uzay grubu) kullanılarak oluşturulmuştur. Model, sistemdeki atomların etkileşme durumlarına göre iki ayrı kısımdan oluşmaktadır. Nanotelin orta kısmındaki $\mathrm{Cu}$ (kırmızı) ve $\mathrm{Ti}$ atomları (mavi), stresin enine bileşenlerini $\left(\sigma_{\mathrm{xx}}\right.$ ve $\left.\sigma_{\mathrm{yy}}\right)$ sifira yakın tutmak ve nanotelin serbestçe küçülmesini veya genişlemesini sağlamak için atomlar arası kuvvet altında serbestçe etkileşime girebilirken, nanotelin tüm uzunluğunun \%20'sine karşılık gelen her iki uçtaki kısımlardaki $\mathrm{Cu}$ ve Ti atomları (yeşil) düzenli örgü noktalarına sabitlenmiş ve

\begin{tabular}{|c|c|c|c|c|c|}
\hline \multicolumn{2}{|c|}{ Metal $r_{e}(\AA)$} & \multirow{2}{*}{$\begin{array}{l}f_{e} \\
1,554485\end{array}$} & \multirow{2}{*}{$\begin{array}{l}\boldsymbol{\rho}_{\boldsymbol{e}} \\
21,175871\end{array}$} & \multirow{2}{*}{$\begin{array}{l}\boldsymbol{\rho}_{s} \\
21,175395\end{array}$} & \multirow{2}{*}{$\begin{array}{l}\boldsymbol{\alpha} \\
8,127620\end{array}$} \\
\hline & 2,556162 & & & & \\
\hline & 2,933872 & 1,863200 & 25,565138 & 25,565138 & 8,775431 \\
\hline & $\beta$ & $A(\mathrm{eV})$ & $B(\mathrm{eV})$ & $\boldsymbol{\kappa}$ & $\lambda$ \\
\hline & $\overline{4,334731}$ & 0,396620 & 0,548085 & 0,308782 & 0,756615 \\
\hline \multirow[t]{2}{*}{$\mathrm{Cu}$} & 4,680230 & 0,373601 & 0,570968 & 0,500000 & 1,000000 \\
\hline & $F_{n 0}(\mathrm{eV})$ & $F_{n I}(\mathrm{eV})$ & $F_{n 2}(\mathrm{eV})$ & $F_{n 3}(\mathrm{eV})$ & $F_{0}(\mathrm{eV})$ \\
\hline \multirow[t]{5}{*}{$\mathbf{T i}$} & $-2,170269$ & $-0,263788$ & 1,088878 & $-0,817603$ & $-2,190000$ \\
\hline & $-3,203773$ & $-0,198262$ & 0,683779 & $-2,321732$ & $-3,220000$ \\
\hline & $F_{1}(\mathrm{eV})$ & $F_{2}(\mathrm{eV})$ & $F_{3}(\mathrm{eV})$ & $\eta$ & $F_{e}(\mathrm{eV})$ \\
\hline & $\overline{0}$ & 0,561830 & $-2,100595$ & 0,310490 & $-2,186568$ \\
\hline & 0 & 0,608587 & $-0,750710$ & 0,558572 & $-3,219176$ \\
\hline
\end{tabular}
birbirleri ile etkileşimine izin verilmemiştir. Periyodik sınır koşulları germe ile eş eksenli olacak şekilde [001] doğrultusunda uygulanmıştır. Benzetim hücresinin boyu $177,57 \AA\left(30 c_{0}\right)$ seçilmiştir.

Tablo 1. Saf $\mathrm{Cu}$ ve Ti için GAM potansiyel parametreleri.

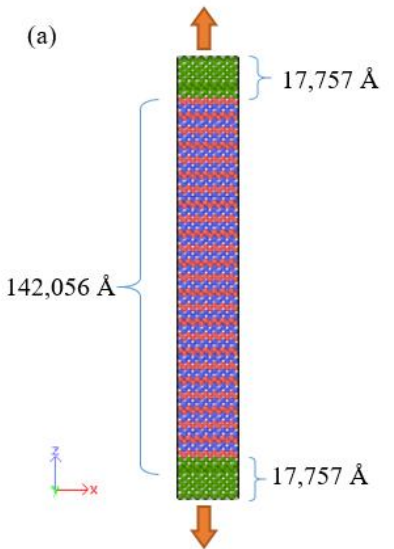

(b)

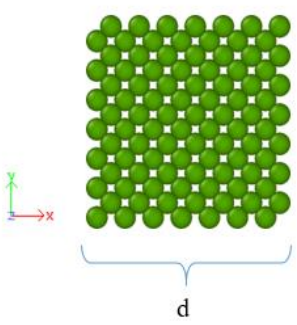

Sekil 1. $2,2 \mathrm{~nm} \gamma \mathrm{CuTi}$ nanotel için atomistik modelin a) yandan ve b) üstten görünüşü. Kırmızı ve mavi atomlar sırasıyla hareketli $\mathrm{Cu}$ ve $\mathrm{Ti}$ atomlarını, yeşil atomlar ise sabit $\mathrm{Cu}$ ve Ti atomlarını temsil etmektedir. d enine kesit uzunluğudur.

Boyutlar1 $4 \mathrm{a}_{\mathrm{o}} \times 4 \mathrm{a}_{\mathrm{o}} \times 30 \mathrm{c}_{\mathrm{o}}$ (1920 atom), $7 \mathrm{a}_{\mathrm{o}} \times 7 \mathrm{a}_{\mathrm{o}} \times 30 \mathrm{c}_{\mathrm{o}}(5880$ atom), $11 \mathrm{a}_{\mathrm{o}} \times 11 \mathrm{a}_{0} \times 30 \mathrm{c}_{\mathrm{o}}$ (14520 atom), $14 \mathrm{a}_{\mathrm{o}} \times 14 \mathrm{a}_{0} \times 30 \mathrm{c}_{\mathrm{o}}$ (23520 atom), $17 \mathrm{a}_{0} \times 17 \mathrm{a}_{0} \times 30 \mathrm{c}_{\mathrm{o}} \quad(34680$ atom), $20 \mathrm{a}_{0} \times 20 \mathrm{a}_{0} \times 30 \mathrm{c}_{\mathrm{o}}$ (48000 atom), $25 \mathrm{a}_{0} \times 25 \mathrm{a}_{0} \times 30 \mathrm{c}_{\mathrm{o}}(75000$ atom), $30 \mathrm{a}_{0} \times 30 \mathrm{a}_{\mathrm{o}} \times 30 \mathrm{c}_{\mathrm{o}}\left(108000\right.$ atom), $35 \mathrm{a}_{0} \times 35 \mathrm{a}_{\mathrm{o}} \times 30 \mathrm{c}_{\mathrm{o}}$ (147000 atom) ve $40 a_{0} \times 40 a_{o} \times 30 c_{o}(192000$ atom) ve enine kesitleri sirasiyla $1,2 \mathrm{~nm}, 2,2 \mathrm{~nm}, 3,4 \mathrm{~nm}, 4,3 \mathrm{~nm}$, $5,2 \mathrm{~nm}, 6,2 \mathrm{~nm}, 7,7 \mathrm{~nm}, 9,3 \mathrm{~nm}, 10,8 \mathrm{~nm}$ ve $12,4 \mathrm{~nm}$ olan aynı boyda on model oluşturulmuştur. Her bir nanotele, $3 \times 10^{-3} \mathrm{ps}^{-1}\left(33 \times 10^{4} \mathrm{MD}\right.$ adim), $2 \times 10^{-3} \mathrm{ps}^{-1}$ (50x10 $0^{4} \mathrm{MD}$ adim), $1 \times 10^{-3} \mathrm{ps}^{-1}\left(10 \times 10^{5} \mathrm{MD}\right.$ adim), $5 \times 10^{-}$ ${ }^{4} \mathrm{ps}^{-1}\left(20 \times 10^{5} \mathrm{MD}\right.$ adim) ve $1 \times 10^{-4} \mathrm{ps}^{-1}\left(10 \times 10^{6} \mathrm{MD}\right.$ adım) şeklinde beş farklı germe oranı ile tek eksenli germe uygulanmıştır. Malzemede indüklenecek şok ve dengesizliği gidermek için yüklemeden önce enerji minimizasyonu yapıldıktan sonra elde edilen kararl sistem sabit atom sayıs, hacim ve enerji (NVE) topluluğu kullanılarak 1 fs zaman aralıklı 50000 MD adımında gevşetme sürecine tabi tutulmuştur. Gevşetilen nanotellere sabit atom sayısı, hacim ve sicaklık (NVT) topluluğuna uygun olarak \%100 deformasyon elde edilene kadar tek eksen boyunca germe uygulanmıştır. Newton'un hareket denklemlerini çözmek için VelocityVerlet algoritması, basınç ve sıcaklığı kontrol etmek için 
Nosé-Hoover barostat ve termostat kullanılmıștır [33]. Sistemin gerilim tensörü, virial stres kullanılarak hesaplanmıştır [34]. Yüzey etkilerini gözlemek adına aynı germe işlemi ideal B11 kristal yapısında $10 \mathrm{a}_{\mathrm{o}} \times 10 \mathrm{a}_{\mathrm{o}} \times 10 \mathrm{c}_{\mathrm{o}}$ (4000 atom) boyutundaki bulk $\gamma \mathrm{CuTi}$ sistemine de uygulanmıștır. Nanotelden farklı olarak bulk sistem germe aşamasında izotermal-izobarik (NPT) topluluk sınırları içinde ele alınmıştır.

\section{BULGULAR}

MD benzetim yöntemlerinin güvenilir sonuçlar verebilmesinin ilk ve en önemli koşulu sistemdeki atomik etkileşmeleri en doğru ve hızlı bir şekilde tanımlayan transfer edilebilir bir atomlar arası çiftler potansiyelden geçer. Diğer bir değişle, seçilen potansiyelin sistemin temel fiziksel ve mekanik (elastik sabitler, poisson oranı, sıkışma ve kayma modülü gibi) özelliklerini doğru ve güvenilir bir şekilde açıklaması beklenir. $\gamma \mathrm{CuTi}$ alaşımının en kararlı kristal yapısı olan B11 yapısı için hesaplanan bazı fiziksel ve mekanik özellikler daha önce rapor edilen deneysel ve diğer teorik yöntemlerle elde edilen değerlerle karşılaştırmalı olarak Tablo 2'de verilmiştir. Elde edilen sonuçların literatürde aynı sistem için rapor edilen deneysel ve diğer teorik sonuçlara oldukça yakın olması $\mathrm{Cu}$ ve Ti atomları arasındaki etkileşmeleri tanımlamak için seçilen GAM potansiyelinin düşük sıcaklıklarda katı sistemin fiziksel ve mekanik özelliklerini doğru ve güvenilir bir şekilde açıklayabildiğini göstermektedir.

Tablo 2. $\gamma \mathrm{CuTi}$ (B11) kristal yapısı için GAM potansiyeli kullanılarak hesaplanan bazı fiziksel ve mekanik özellikler.

\begin{tabular}{lll}
\hline & Bu Çalışma & Diğer Çalışmalar \\
\hline $\mathbf{a}(\AA)$ & 3,1485 & $3,1070^{\mathrm{a}}, 3,1080^{\mathrm{b}}$ \\
$\mathbf{c}(\AA)$ & 5,9981 & $5,9190^{\mathrm{a}}, 5,8870^{\mathrm{b}}$ \\
$\mathbf{E}(\mathbf{e V} /$ atom) & $-4,3903$ & $-4,2800^{\mathrm{c}}$ \\
\hline Elastik Sabitler & & \\
\hline $\mathbf{C}_{\mathbf{1 1}}$ (GPa) & 109,2620 & $177,5600^{\mathrm{d}}$ \\
$\mathbf{C}_{\mathbf{1 2}}$ (GPa) & 103,7947 & $102,6600^{\mathrm{d}}$ \\
$\mathbf{C}_{\mathbf{1 3}}$ (GPa) & 97,2685 & $103,1500^{\mathrm{d}}$ \\
$\mathbf{C}_{\mathbf{3 3}}$ (GPa) & 130,9425 & $185,6500^{\mathrm{d}}$ \\
$\mathbf{C}_{\mathbf{4 4}}$ (GPa) & 44,6372 & $66,2000^{\mathrm{d}}$ \\
$\mathbf{C}_{\mathbf{6 6}}$ (GPa) & 81,1075 & $80,9500^{\mathrm{d}}$ \\
Sıkışma Modülü (GPa) $^{\mathrm{d}}$ & 105,1264 & $128,7100^{\mathrm{d}}$ \\
Kayma Modülü (GPa) & 56,7959 & $44,5900^{\mathrm{d}}$ \\
Poisson Oranı & 0,4605 & $0,3400^{\mathrm{d}}$ \\
\hline
\end{tabular}

${ }^{\mathrm{a}}[35],{ }^{\mathrm{b}}[36],{ }^{\mathrm{c}}[37],{ }^{\mathrm{d}}[20]$

Germe boyunca elde edilen gerilim-gerinim eğrileri çalışılan malzemenin temel mekanik özellikleri hakkında faydalı bilgiler sunar. $0,1 \mathrm{~K}^{\prime} \mathrm{de} 1 \times 10^{-3} \mathrm{ps}^{-1}$ germe oranı uygulanan bulk sistem için tek eksenli germe deformasyonunun değişimi Şekil 2(a)'da gösterilmiştir. Germe sürecinin ilk aşamalarında deformasyonun elastik özelliğe sahip olduğu gözlenmiştir. Gerilim-gerinim eğrisinde gerilimin $\sim 1,70 \mathrm{GPa}$ değerine kadar arttı̆̆ bölge \%7,60'a denk gelen ilk yükleme bölgesi olup, bu aşamada deformasyonun elastik özelliğe sahip olduğunu gösterir. Germenin artmasıyla birlikte elastik bölgenin sınırı ile sistemin kırılma noktası arasındaki bölgede $(1,7062$ - 5,9865 GPa) plastik deformasyon başlamakta ve gerilim-gerinim eğrisi eğim değiştirerek lineer artışını \%34,58 gerinim değerine kadar devam ettirmektedir. Plastik bölgede dislokasyonların oluşması ile birlikte gerilim-gerinim eğrisinde 5,9865 $\mathrm{GPa}$ gerilim ve 0,3458 gerinim değerlerine karşılık gelen noktada ani ve bir o kadar da keskin bir düşüş gözlenmiştir. Artan gerinimle, gerilim-gerinim eğrisi zikzaklar şeklinde azalan- artan bir döngüye girmektedir. Sistemin elastik şekil değiştirmesinin bir ölçüsü olan Elastisite Modülü, bütün sistemler için elde edilen gerilim-gerinim eğrilerinin lineer artış gösterdiği bölgenin eğiminden yararlanılarak grafik metodu ile belirlenmiştir. Germe altında $0,1 \mathrm{~K}$ 'de ve $1 \times 10^{-3} \mathrm{ps}^{-1}$ germe oranı için Bulk sistemin gerilimgerinim eğrisine uygulanan fit prosedürü Şekil 2(b)'de gösterilmiştir. Bu prosedürde lineer davranış sergileyen gerilim-gerinim eğrisinin tamamını almak yerine hem bulk hem de nanoteller için elastik davranışı garanti altına alabilmek adına yalnızca \% 2'lik gerinim göz önüne alınmıştır.

Tablo 3'te bulk sistem için 0,1 K'de farklı germe oranları için elde edilen Elastisite Modülü değerleri listelenmiştir. Farklı germe oranları altında hesaplanan Elastisite Modülleri aynı aralıkta salınım yapmaktadır. Buna göre $\gamma \mathrm{CuTi}$ için Elastisite Modülü uygulanan germe oranından bağımsız olduğu gözlenmiştir.
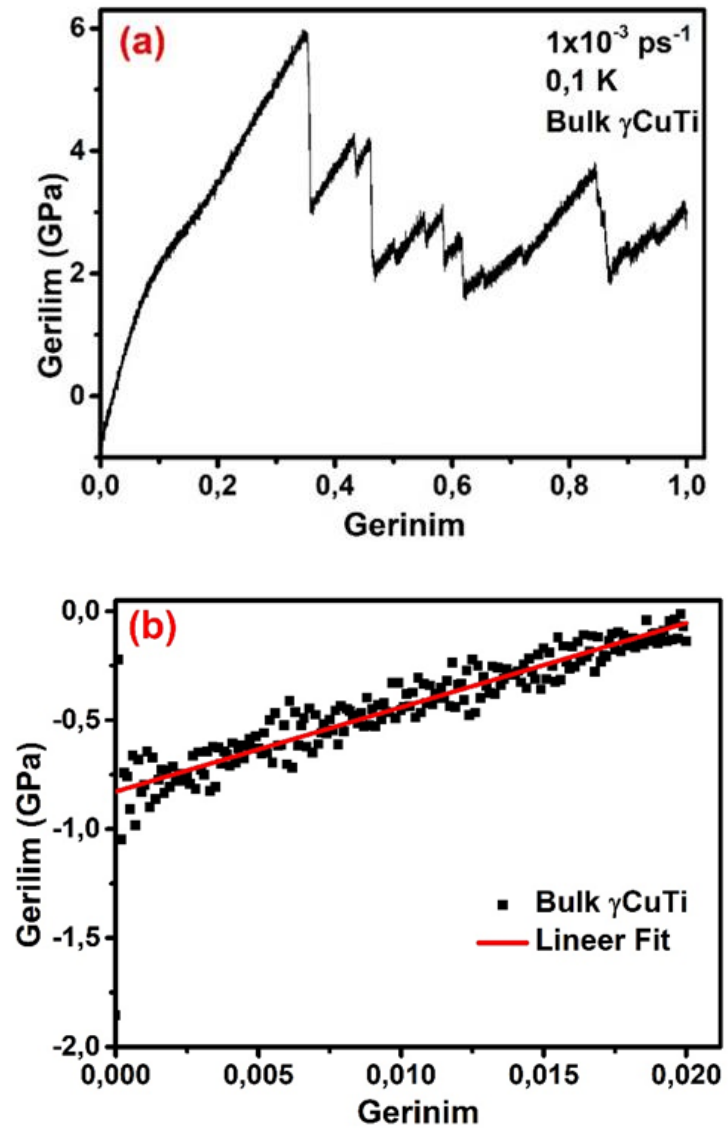

Şekil 2. Bulk $\gamma \mathrm{CuTi}$ sistemi için $0,1 \mathrm{~K}$ 'de ve $1 \times 10^{-3} \mathrm{ps}^{-1}$ germe oranı altında a) \%100 ve b) \%2 'lik uzama için gerilim-gerinim eğrisi.

Tablo 3. Bulk $\gamma \mathrm{CuTi}$ için $0,1 \mathrm{~K}$ 'de farklı germe oranları altında hesaplanan Elastisite Modül değerleri.

\begin{tabular}{ll}
\hline Germe Oranı & $\begin{array}{l}\text { Elastisite Modülü } \\
(\mathbf{G P a})\end{array}$ \\
\hline $3 \times 10^{-3}$ & 39,8245 \\
$2 \times 10^{-3}$ & 40,0097 \\
$1 \times 10^{-3}$ & 38,7110 \\
$5 \times 10^{-4}$ & 39,1199 \\
$1 \times 10^{-4}$ & 40,5859 \\
\hline
\end{tabular}


Potansiyel enerji (PE) değişiminden yararlanarak malzemelerin elastik, plastik ve kırılma davranışları gibi mekanik özellikleri hakkında derinlemesine bilgi elde edinilebilir. PE ve sistemin gerilimi arasındaki ilişkiyi daha iyi anlayabilmek için, Şekil 3(a)'da 2,2 nm boyutlu nanotel için $0,1 \mathrm{~K}$ ve $1 \times 10^{-4} \mathrm{ps}^{-1}$ germe oranı altındaki gerilim-gerinim eğrisi ile atom başına PE-gerinim eğrisi bir arada verilmiştir. Tekrardan kaçınmak için diğer nanotellerin sonuçları bu grafikte verilmemiştir. Daha basit ve ayrıntıll bir tartışma yapabilmek için gerilimgerinim eğrisinin davranışı göz önüne alınarak şekil, elastik bölge, plastik bölge, plastik bölgenin boyun ve kırılma kısmı olmak üzere dört kısıma ayrılmıştır. \%5 gerinim değerine kadar tam elastik deformasyonun gerçekleştiği I. bölgede, gerilim ve atom başına PE surasiyla 2,596 GPa ve $-4,097 \mathrm{eV} /$ atom değerlerine kadar lineer olarak artmaktadır. Elastik deformasyonun sınırındaki gerilim ve gerinim sırasıla akma gerilimi ve akma gerinimi olarak adlandırılır. Daha yüksek PE 'ye sahip atomların malzemenin yüzey bölgesine yerleşmesiyle oluşan deformasyonun neticesinde akma gerçekleşir [38]. Elastik bölgede atomlar arası bağlar gerinim ile birlikte homojen olarak uzar, uygulanan kuvvet veya yük kaldırıldığında atomlar arası bağlar kısalır ve sistem ilk haline geri döner. II. bölgede PEgerinim eğrisi farklı bir eğim ile lineer artışa devam ederken gerilim-gerinim eğrisi önce hafif bir azalmaartma davranışından sonra daha farklı bir eğimle 4,572 $\mathrm{GPa}$ değerine kadar artmaya devam eder. Malzeme içerisindeki düzlemler (tabakalar), uygulanan yüklemenin neticesinde atomlar arası bağların uzamasıyla birlikte kaymaya (dislokasyon) başlar. Yük kaldırılsa dahi, düzlemler halen kaymaya devam eder ve sistem artık kalıcı bir deformasyona uğramış olur yani deformasyon davranışı plastiktir. Bundan sonra hem gerilim-gerinim hem de PE-gerinim eğrisi \% 26,5 gerinime denk gelen noktada ani ve keskin bir düşüs gösterir. $\mathrm{Bu}$ davranış, plastik deformasyon bölgesinde dislokasyonların artması ve bunun neticesinde nanotelin kesit alanının küçülerek nanotelde "boyun" oluşması anlamını taşımaktadır. Eğrinin zirve noktasına karşılık gelen gerilim ve gerinim sirasıyla maksimum gerilim ve boyun gerinimi olarak adlandırılır. III. bölgede gerilim ve PE, \% 29 gerinime kadar azalmaktadır ki bu da 2,2 $\mathrm{nm}$ boyutundaki nanotelin kırılması anlamına gelir ve bu gerinim değeri kırılma gerinimi olarak adlandırılır. Plastik deformasyonun sinırı olan IV. bölgede gerilim değeri sıfır civarında salınırken PE limit değerine ulaşmak için artışını sürdürmektedir. $\mathrm{Bu}$ nanotelin elastik geri kazanımın göstermek için PE ve sistemin hacminin benzetim süresine bağlı değişimi Şekil 3(b)'de bir arada verilmiştir. Şekildeki kesikli düşey çizgi elastik bölgenin sınırını gösterir $(0,05$ gerinim, 500 ps 'ye karşılık gelir). Elastik bölge sınırında germe kaldırılarak sistemin NPT topluluğu içinde minimum enerji durumuna ulaşmasına izin verildiğinde, PE ( -4,11 eV/atom) ve hacim $\left(\sim 52,09 \AA^{3} /\right.$ birim hücre) başlangıç değerlerine geri döner ve yaklaşık bu değerler etrafında salınmaya devam eder. 2,2 $\mathrm{nm}$ boyutlu nanotelin germe deformasyonu sırasında farklı germe oranları için PEgerinim eğrileri Sekil 3(c)'de ve farklı boyutlardaki nanotellerin $1 \times 10^{-3} \mathrm{ps}^{-1}$ germe oranı altındaki PE-gerinim eğrilerini Şekil 3(d)'de gösterilmiştir. Şekil 3(c)'deki
PE-gerinim eğrilerinin davranışlarını da SSekil 3(a)'daki gibi dört bölgeye ayırarak tartışmak mümkündür. Genel olarak farklı germe oranları için elde edilen PE-gerinim eğrileri I., II. ve IV. bölgelerde benzer davranışsal hareketler gösterse de, boyun oluşumu sebebiyle III. bölgede germe oranına bağlı olarak düşüş davranışı sergilemektedir. Bütün germe oranlarındaki düşüşün sebebi, germe boyunca bu bölgedeki atomlar arası bağların kırılmasıyla açığa çıkan bağ enerjisi sebebiyle artan atomik hareketliliğin nanotelin düzenli kristal yapısını bozmasıdır. $\mathrm{Bu}$ davranıș șöyle detaylandırılabilir: $3 \times 10^{-3} \mathrm{ps}^{-1}, 2 \times 10^{-3} \mathrm{ps}^{-1}$ ve $1 \times 10^{-3} \mathrm{ps}^{-1}$ germe oranları için PE'nin düşüş miktarları belli belirsiz veya daha yumuşak iken, germe oranındaki azalışa ( $3 \times 10^{-3} \mathrm{ps}^{-1}$, den $1 \times 10^{-4} \mathrm{ps}^{-1}$,ye) bağlı olarak PE 'nin ani düşüş miktarı artmaktadır. $5 \times 10^{-4} \mathrm{ps}^{-1}$ ve $1 \times 10^{-4} \mathrm{ps}^{-1}$ germe oranları için ise PE'deki düşüş miktarları çok daha belirgin ve keskin bir hal almaktadır. PE'deki keskin düşüşün sebebi, bu bölgede nanotelin boyun vermesi ve bunun bir neticesi olarak nanotelin boyunun hızlı bir şekilde incelmesi ve nihayetinde kırılmasıdır. Keskin düşüşlerinin aksine yumuşak düşüşler ise malzemenin boyun bölgesinin germe deformasyonuna karşı daha fazla dayanıklılık gösterip diğerlerine göre daha çok esneyerek kırılmasıyla açıklanabilir. Boyuta bağlı PE-gerinim ilişkisi aynı eğrinin yukarıda tartışılan germe oranına bağlılığına oldukça benzerdir: yine I., II. ve IV. bölgelerde çok belirgin bir farkl1l1k gözlenmezken, III. bölgede ise farklılıklar gözlenmiştir. III. bölgedeki bu farklı davranışları şu şekilde açıklamak mümkün olabilir; eksik komşu sayısına sahip yüzey atomlarının PE'ye katkısının daha fazla olduğu ince nanotellerde PE değerindeki düşüş daha belirgin olmaktadır ve nanotel boyutunun artmasiyla PE'nin değerindeki düşme daha yumuşar. Bulk sistem için ise PE-gerinim eğrisi, kırılma olmadan belirli bir doygunluk seviyesi (lütfen Şekil 2(a)'ya bakınız) etrafında salınmaktadır. Genel olarak; germe deformasyonu sürecinde nanotelin boyutu arttıkça, nanotelin PE azalmış ve aynı germe koşulları altında bulk malzeme değerine doğru yaklaşmıştır.

Germe deformasyonu sürecinde nanotellerde meydana gelen değişim, $0,1 \mathrm{~K}^{\prime}$ de ve $1 \times 10^{-4} \mathrm{ps}^{-1}$ germe oranı altındaki 2,2 nm boyutlu nanotelin farklı gerinimlerdeki atomik konfigürasyonlarının anlık görüntülerinin verildiği Şekil 4(a)-(f)'den gözlenebilir. Germe işlemi öncesi uygulanan enerji minimizasyonu ve dengeleme sürecinden sonra atomların düzenli kafes noktalarına yerleştikleri Şekil 4(a)'da açıkça görülebilmektedir. Şekil 4(b)'deki nanotel görüntüsü 0,050 akma gerinimine (elastik deformasyon limiti) karşı11k gelmektedir. $\mathrm{Bu}$ evrede, nanotelin boyunun uzamasına ve atomlar arası mesafenin artmasına rağmen malzemede kalıcı bir deformasyonun oluşmamaktadır. Şekil 4(c), plastik deformasyonun gözlendiği fakat nanotelin şeklinin bozulmadığı SSekil 3(a)' da verilen II. bölgenin sınırında, gerilimin keskin düşüş yapmadan hemen önceki gerinim değerine karşllık gelen nanotel görüntüsüdür. Şekil 4(d)'de nanotelin ortasından incelmesi ve düzlemlerin birbiri üzerinden kaymasıyla boyun oluşmaktadır. $\mathrm{Bu}$ aşamada (\%26) nanotel esnemeye başlar. Sistemin uzaması için gerekli gerilim, 
boyun bölgesinin kesit alanının küçülmesi nedeniyle azalmıştır (lütfen Şekil 3(a)'ya bakınız). Gerilimin daha da artmasıyla, dislokasyonların artan yoğunluğunu yansitan boyun incel mesi Şekil 4(e)'de görülmektedir. Şekil 4(f)'de nanotel \% 2,46 esnedikten sonra, iki ayrı küme oluşturacak şekilde kırılmıştır. Ayrıca nanotelin boyun verdikten hemen sonra
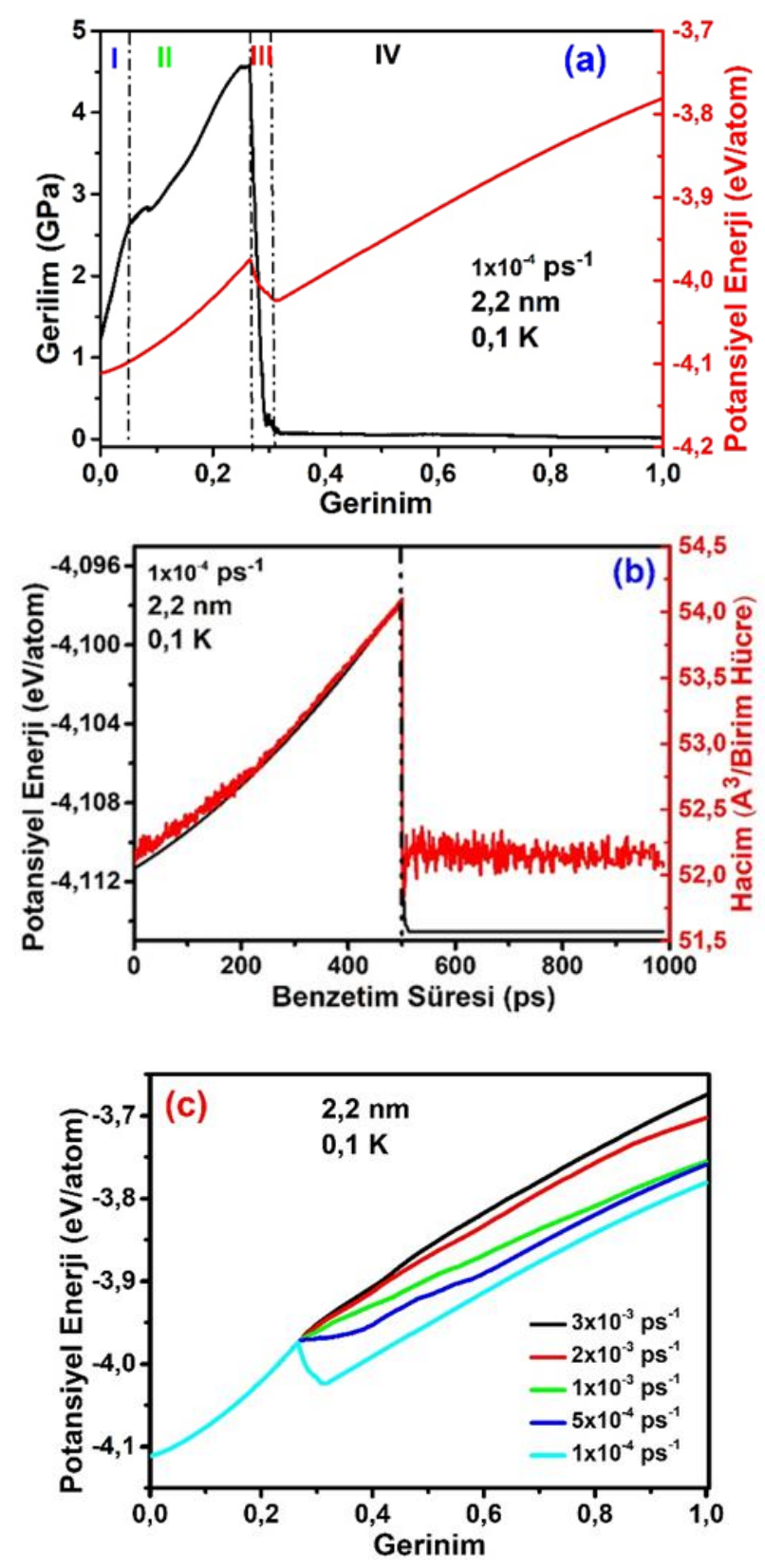

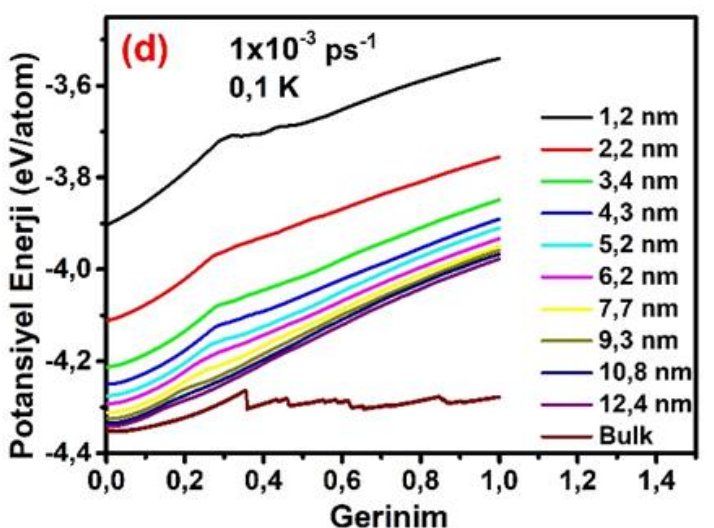

Şekil 3. Germe işlemi sırasında a) $1 \times 10^{-4} \mathrm{ps}^{-1}$ germe oranında $0,1 \mathrm{~K}$ ' de $2,2 \mathrm{~nm}$ nanotel için gerinime bağlı gerilim ve PE ilişkisi (elastik, plastik, boyun ve kırılma kısımları arası noktalı çizgi ile gösterilmiştir). b) Elastik geri kazanım: PE ve hacim gevşeme eğrileri. c) 2,2 nm boyutlu nanotelde PE-germe oranı ilişkisi ve d) $1 \times 10^{-3} \mathrm{ps}^{-1}$ germe oranında PE - boyut ilişkisi.

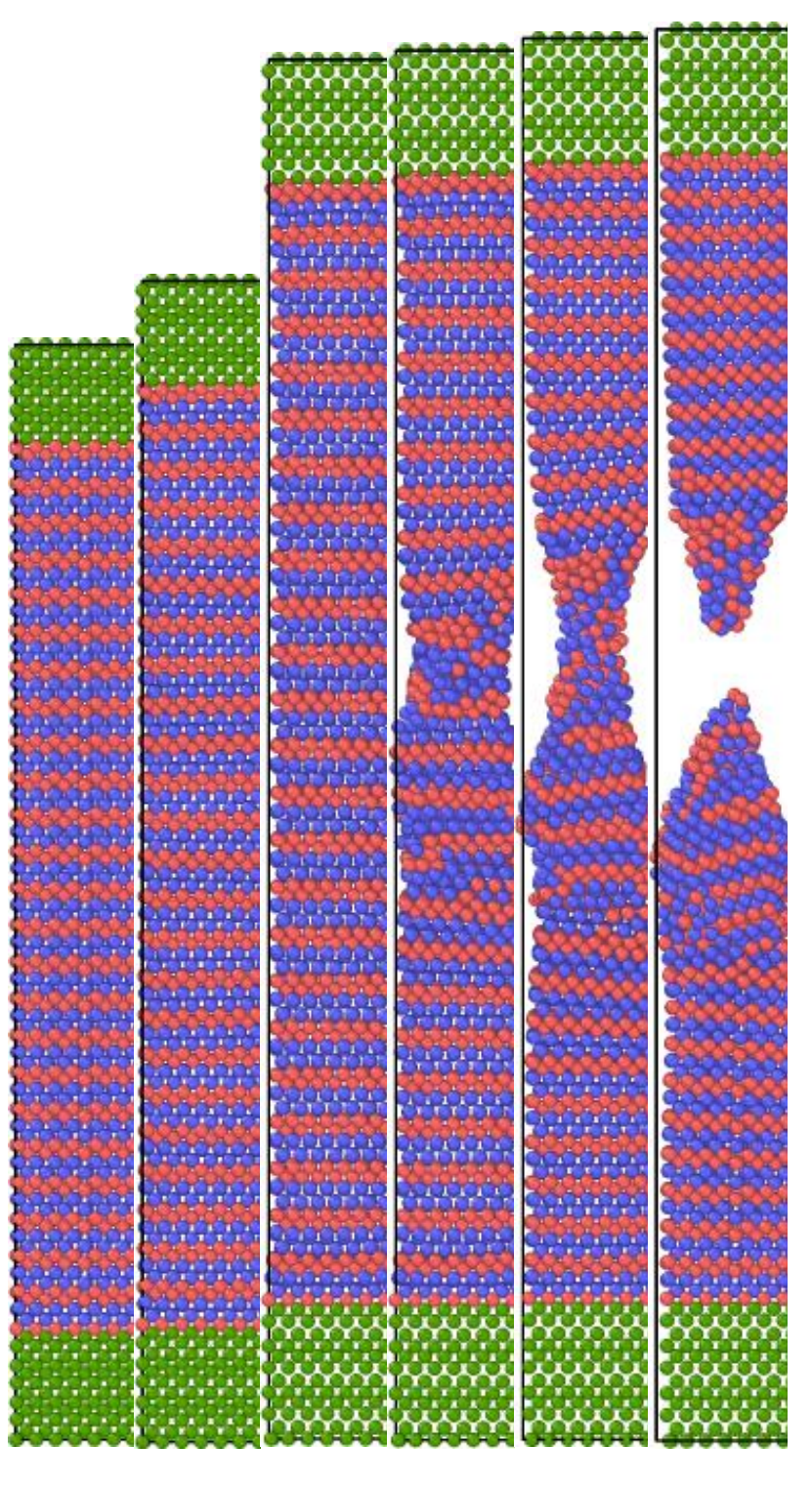

(a) (c) (e) (f)

Şekil 4. $0,1 \mathrm{~K}$ 'de ve $1 \times 10^{-4} \mathrm{ps}^{-1}$ germe oranı altında $2,2 \mathrm{~nm}$ boyutlu nanotelin (a) 0 , (b) 0,050 , (c) 0,260 , (d) 0,265 , (e) 0,280 ve (f) 0,290 gerinim değerlerindeki atomik konfigürasyonları. 
kırılmamas1 nanotelin bu esnada esnediğini göstermektedir. Esneklik üç aşamalı bir döngüde açıklanabilir: birinci aşama, çoklu düzlemsel kaymalar anlamına gelen bir boyun oluşumu, sonra komşu atomlarının boyun bölgesine çekilmesiyle birlikte boynun incelmesi ve son olarak, plastik deformasyonun sonunda meydana gelen esnek kırılmadır.

\subsection{Germe Oranı Etkisi}

Germe oranının germe - gerinim ilişkisine etkisini anlayabilmek için 2,2 $\mathrm{nm}$ boyutlu nanotel için $0,1 \mathrm{~K}^{\prime}$ de beş farklı germe oranı ile hesaplanan gerilim-gerinim eğrileri Şekil (5)'te bir arada gösterilmiştir. Bu eğriler sayesinde hem elastik hem de plastik bölgeler daha iyi tanımlanabilir veya anlaşılabilir. Gerilim - gerinim eğrileri boyun gerinimine kadar neredeyse üst üstedir. Germe oranının, nanotellerin mekanik özelliklerini özellikle elastik deformasyon bölgesinden sonra daha çok etkilediği görülmüştür. Şekil (5)' te verilen gerilim gerinim eğrilerinden yararlanarak hesaplanan akma gerilimi ve gerinimi, maksimum gerilim, boyun ve kırılma gerinimi, esneklik ve Elastisite Modülü değerleri Tablo 4'te listelenmiştir. Elastisite Modülü, farklı germe oranlarında elastik bölgedeki gerilim - gerinim eğrilerinin eğimlerinin neredeyse aynı olmaları nedeniyle germe oranından bağımsızdır. Literatürdeki deneysel çalışmalar, nanoyapıların Elastisite Modül değerlerinin bulk sistemlerden daha farklı olduğunu rapor etmiştir [39-44]. Bu sonuçlara paralel olarak mevcut çalışmada da nanotellerin Elastisite Modül değerlerinin bulk sistemlerden daha düşük olduğu gözlenmiştir. Germe oranı düştükçe, PE'deki azalma nedeniyle akma gerinimi, akma ve maksimum gerilim azalmakta ve boyun gerinimi 0,254-0,265 arasinda salınmaktadır. Plastik bölgenin boyun kısmında, germe oranı azaldıkça gerilimdeki düşüş daha keskin ve belirgin olmaktadır. Germe oranının azalmasıyla birlikte salınımlar azalır. Daha düşük germe oranı altındaki nanotellerde boyun ve kırılma kismı aras1 daha kisa olmakta ve yavaş gerilen nanotelin esnekliğinin daha düşük olduğu görülmektedir: azalan germe oranı ile nanotelde daha erken kırılma gözlenir.

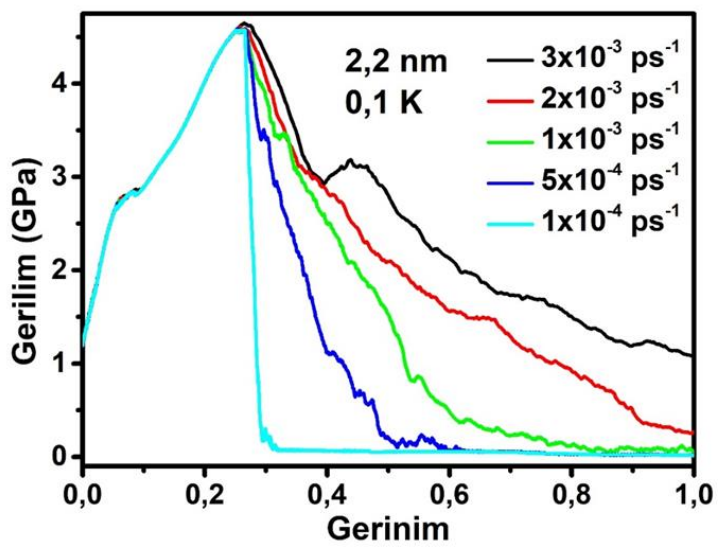

Sekil 5. $0,1 \mathrm{~K}$ 'de $2,2 \mathrm{~nm}$ boyutlu nanotelin farklı germe oranları altındaki gerilim-gerinim eğrileri.

\subsection{Boyut Etkisi}

CuTi nanotellerinde boyuta bağlı deformasyon mekanizması hakkında yorum yapabilmek için $0,1 \mathrm{~K}$ 'de ve $1 \times 10^{-3} \mathrm{ps}^{-1}$ germe oranı altındaki farklı nanotellerin gerilim-gerinim eğrileri Şekil (6)'da bir arada verilmiştir. Şekle bulk sisteme ait hesaplama sonuçları da karşılaştırma amacıyla dâhil edilmiştir. Bütün nanotellerin gerilim-gerinim eğrilerinde belirgin bir ana pik gözlenirken, bulk sistem için ana pikten sonra dört tane daha belirgin pik görülmektedir. Nanoteller farklı kesit büyüklüklerine sahip olmalarına rağmen gerilim gerinim eğrilerinin davranışları küçük farklılıklar dışında birbirlerine oldukça benzerdir. Bunların içinde en küçük boyuta sahip olan 1,2 nm kesit uzunluklu nanoteldeki yüzey etkilerinin diğer nanotellere oranla baskın olmasından dolayı daha fazla dalgalanmalar olmaktadır. Aynı nanotelin gerilim-gerinim eğrisinde boyun geriniminden önce görülen küçük bir omuz, en ince nanotelde daha fazla dislokasyon meydana geldiğini gösterir. Bunun bir sonucu olarak nanotel daha az esner ve daha erken kırılır. Daha büyük boyutlu nanoteller, daha fazla plastik deformasyona ve esnekliğe sahiptir: daha büyük kesit alanı, dislokasyonların hareketini engelleyen dinamik dalga etkisi veya fonon sürüklemesi nedeniyle daha az istatistiksel salınım genliğine sebep olur [45]. Sonuçlar, nanotelin boyutunun artması ile malzemenin esnekliğinin de arttığını göstermektedir. Bu durum akma ve maksimum gerilimin düşmesiyle nanotelin daha yumuşak ve esnek olacağı kavramını destekler.

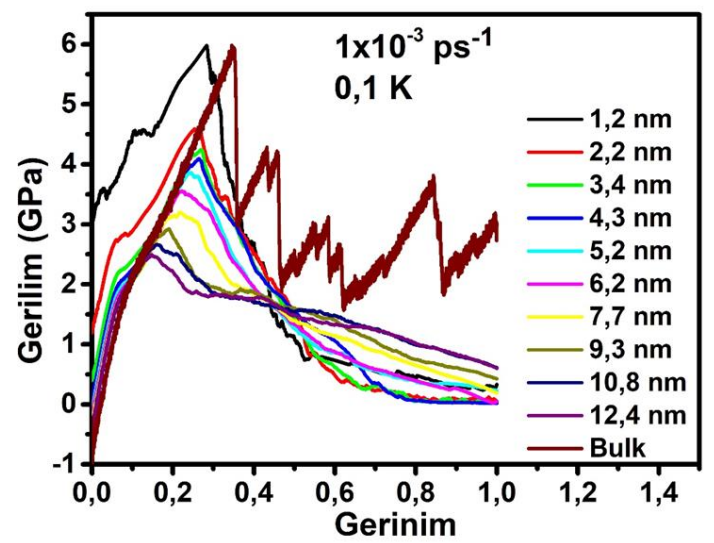

Şekil 6. $0,1 \mathrm{~K}$ ve $1 \times 10^{-3} \mathrm{ps}^{-1}$ germe oranı altında farklı boyutlardaki nanotellerin ve bulk sistemin gerilim-gerinim eğrileri.

Şekil (6)'da farklı boyutlardaki nanoteller için verilen eğrilerden elde edilen akma gerilimi ve gerinimi, boyun ve kırılma gerinimi, maksimum gerilim, esneklik değerleri ve Bulk sistemin ilgili değerleri Tablo 5'te listelenmiştir. Bunların dışında tabloda, germe işlemi öncesi gerilimi olarak alınan başlangıç gerilim değerleri de sunulmuştur. Başlangıç gerilimi, yüzey atomlarından kaynaklanan yüzey gerilimi ve dengedeki çekirdekten gelen gerilimden oluşur. Dengelenmiş nanoteldeki bozulan simetriden doğan yüzey geriliminden dolayı germe öncesi başlangıç gerilimi sıfır değildir. Kalın nanotellere oranla daha fazla kopuk bağlara, yüksek yüzey/iç hacim atom sayısı oranına ve doğal olarak da eksik komşu atom sayısına sahip olan daha küçük boyutlu nanotellerde yüzey gerilimi daha baskındır ve 
başlangıç geriliminin değerini belirler. Boyutun artması ile birlikte başlangıç gerilimi, hiçbir yüzey ve kusura sahip olmayan bulk sınırına azalarak yaklaşır. İnce nanotellerin kisitlı aktivasyon hacmi içinde kusur çekirdeklenmesi için gereken olası konum sayısının daha az olmasi [46] sebebiyle nanoteldeki akma gerilimi başlangıç gerilimi, boşluk ve dislokasyon çekirdeklenmesi ile bağlantılı olan boyut etkileri ile ilişkilendirilebilir [47-49]. Deformasyonu başlatmak için gereken dış gerilim, nanotelin başlangıç geriliminden büyük olmalıdır. Boyut arttıkça akma gerilimi, aynı başlangıç gerilimi gibi azalarak bulk limitine yaklaşır.
Daha yüksek başlangıç gerilimine sahip olan ve daha yüksek PE'li ince nanoteller, kalın nanotellere göre daha fazla akma gerilimine sahiptir. Elde edilen sonuçlara göre akma geriliminin boyuta bağlı davranışı, deneysel verilerle [50,51] doğrulanan Hall-Petch ilişkisi [52] ile tutarlıdır. Yüzey gibi hiçbir kusuru olmayan bulk malzeme, dislokasyon olmadan $1,7062 \mathrm{GPa}$ akma gerilimi ve 0,0760 akma gerinimine kadar elastik davranışını korur.

Tablo 4. 0,1 K'de 2,2 nm boyutlu nanotel için farklı germe oranları altında hesaplanan bazı mekanik özellikler.

\begin{tabular}{|c|c|c|c|c|c|c|c|}
\hline $\begin{array}{l}\text { Germe } \\
\text { Oranı }\end{array}$ & $\begin{array}{l}\text { Akma } \\
\text { Gerinimi }\end{array}$ & $\begin{array}{l}\text { Akma } \\
\text { Gerilimi } \\
\text { (GPa) }\end{array}$ & $\begin{array}{l}\text { Maksimum } \\
\text { Gerilim } \\
\text { (GPa) }\end{array}$ & $\begin{array}{l}\text { Boyun } \\
\text { Gerinimi }\end{array}$ & $\begin{array}{l}\text { Kirılma } \\
\text { Gerinimi }\end{array}$ & $\begin{array}{l}\text { Esneklik } \\
(\%)\end{array}$ & $\begin{array}{l}\text { Elastisite } \\
\text { Modülü } \\
\text { (GPa) }\end{array}$ \\
\hline $3 \times 10^{-3}$ & 0,0631 & 2,7698 & 4,6475 & 0,2644 & 0,8900 & 62,5600 & 28,1156 \\
\hline $2 \times 10^{-3}$ & 0,0537 & 2,6607 & 4,6070 & 0,2566 & 0,8800 & 62,3400 & 28,6571 \\
\hline $1 \times 10^{-3}$ & 0,0535 & 2,6489 & 4,5922 & 0,2537 & 0,5300 & 27,6300 & 27,7388 \\
\hline $5 \times 10^{-4}$ & 0,0524 & 2,6389 & 4,5926 & 0,2542 & 0,4900 & 23,5800 & 27,9100 \\
\hline $1 \times 10^{-4}$ & 0,0500 & 2,5965 & 4,5720 & 0,2654 & 0,2900 & 2,4600 & 27,9187 \\
\hline
\end{tabular}

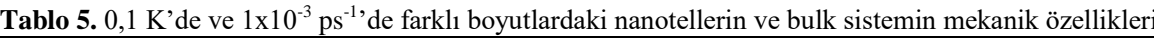

\begin{tabular}{|c|c|c|c|c|c|c|c|}
\hline Boyut & $\begin{array}{l}\text { Başlangıç } \\
\text { Gerilimi } \\
\text { (GPa) }\end{array}$ & $\begin{array}{l}\text { Akma } \\
\text { Gerinimi }\end{array}$ & $\begin{array}{l}\text { Akma } \\
\text { Gerilimi } \\
\text { (GPa) }\end{array}$ & $\begin{array}{l}\text { Maksimum } \\
\text { Gerilim } \\
\text { (GPa) }\end{array}$ & $\begin{array}{l}\text { Boyun } \\
\text { Gerinimi }\end{array}$ & $\begin{array}{l}\text { Kırılma } \\
\text { Gerinimi }\end{array}$ & $\begin{array}{l}\text { Esneklik } \\
(\%)\end{array}$ \\
\hline Bulk & $-1,8559$ & 0,0760 & 1,7062 & 5,9865 & 0,3458 & - & - \\
\hline $1,2 \mathrm{~nm}$ & 2,9973 & 0,0279 & 3,5922 & 5,9801 & 0,2837 & 0,4500 & 16,6300 \\
\hline $2,2 \mathrm{~nm}$ & 1,1920 & 0,0535 & 2,6489 & 4,5922 & 0,2537 & 0,5300 & 27,6300 \\
\hline $3,4 \mathrm{~nm}$ & 0,4003 & 0,0670 & 2,2106 & 4,2434 & 0,2708 & 0,6500 & 37,9200 \\
\hline $4,3 \mathrm{~nm}$ & 0,1163 & 0,0683 & 2,0317 & 4,0939 & 0,2642 & 0,6800 & 41,5800 \\
\hline $5,2 \mathrm{~nm}$ & $-0,0912$ & 0,0696 & 1,9311 & 3,8618 & 0,2409 & 0,7500 & 50,9100 \\
\hline $6,2 \mathrm{~nm}$ & $-0,1589$ & 0,0716 & 1,8798 & 3,5539 & 0,2226 & 0,8100 & 58,7400 \\
\hline $7,7 \mathrm{~nm}$ & $-0,3009$ & 0,0716 & 1,8205 & 3,1979 & 0,2178 & 0,8600 & 64,2200 \\
\hline $9,3 \mathrm{~nm}$ & $-0,3708$ & 0,0705 & 1,7935 & 2,9250 & 0,1900 & - & - \\
\hline $10,8 \mathrm{~nm}$ & $-0,3818$ & 0,0700 & 1,7899 & 2,6608 & 0,1609 & - & - \\
\hline $12,4 \mathrm{~nm}$ & $-0,4525$ & 0,0702 & 1,7863 & 2,2705 & 0,1124 & - & - \\
\hline
\end{tabular}

Bulk malzemenin elastik davranışı nanoteller ile kıyaslandığında çok daha uzun sürmektedir. Akma geriniminin boyuta bağlı davranışı, PE'nin boyuta bağlı davranışı ile benzerdir (lütfen Şekil 3(d)'ye bakınız). Silindirik bir nanotelin kristalografik doğrultuda kararlı yüzeyleri olmamasına rağmen, B11 kristal yapısında kurulan $\gamma \mathrm{CuTi}$ nanotelleri belirli kristalografik doğrultularda kararlı yüzeylere sahiptir. Boyut arttıkça nanotel yüzeyinde bulunan atom sayısı da artar ve yüzey enerjisindeki istatistiksel dalgalanmalar azalarak daha kararlı yüzey oluşur. Bunun sonucu olarak akma gerinimi artararak bulk limitine ulaşır. İnce nanoteller yüksek PE ve başlangıç gerilimine sahip olduklarından kalın nanotellere göre daha yüksek maksimum gerilime sahiptir ve daha geç boyun verirler. Kalın nanotellerin enine kesit alanı büyük olduğu için elastik ve plastik deformasyona daha fazla dayanırlar ve böylece boyut arttıkça esneklik ve kırılma gerinimi artarak bulk limitine doğru yaklaşır. Öyle ki $9 \mathrm{~nm}$ 'den daha kalın nanotellerde kırılma gözlenmemiştir.

Şekil 7'de Elastisite Modülünün boyuta bağl1lığ1, doğrusal elastik mekanik davranış varsayımı ile hesaplanarak gösterilmektedir. Şekil 7 yüzey etkilerinin baskınlığına göre üç bölgeye ayrılmıştır: 1,2 nm 'den 4,3 nm 'ye kadar geçerli I. bölgede bir sınır değere ulaşacak şekilde hızlı artış gözlenmektedir. Bu artış gerilimgerinim eğrisinin elastik bölgedeki davranışından da açıkça görülebilir. Nanotelin yüzey alanının tüm hacmine oranının büyük olduğu bu bölgede yüzey etkilerinin baskınlığı net bir şekilde görülebilmektedir. Yüzey gerilimi ve nanotelin çekirdek kısmındaki gerilimin dengeli olduğu 4,3-7,7 nm arasındaki II. bölgede Elastisite Modül değeri ortalama $\sim 34 \mathrm{GPa}$ civarındadır. Son olarak III. bölgede nanotelin çekirdek kısmındaki iç gerilim baskın olup kesit uzunluğunun 12,4 nm'ye kadar artmasıyla birlikte Elastisite Modülü aşamalı bir şekilde artarak bulk limitine doğru yaklaşmaktadır. Mevcut çalışmada CuTi nanotellerinin Elastisite Modüllerinin boyuta bağlı davranışı ile ilgili sonuçlar ve gözlemler, daha önceki yıllarda farklı araştırmacılar tarafindan $\mathrm{Cu}$ [10], $\mathrm{TiO}_{2}$ [53] ve $\mathrm{Cu}-\mathrm{Ag}$ [54] nanotelleri için rapor edilen sonuçlar ile benzerdir. 


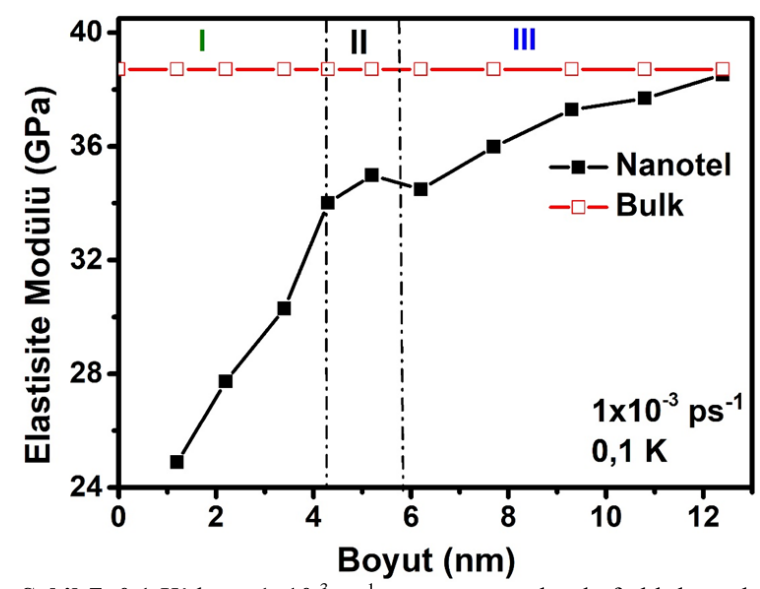

Şekil 7. $0,1 \mathrm{~K}$ 'de ve $1 \times 10^{-3} \mathrm{ps}^{-1}$ germe oranı altında farklı boyutlardaki nanoteller ve Bulk sistem için Elastisite Modül değerlerinin değişimi.

\section{SONUÇ}

Mevcut çalışmada, B11 tipi kristal yapıda oluşturulan $\gamma \mathrm{CuTi}$ nanotellerinin germe oranı ve boyuta bağlı mekanik özelliklerini araştırmak için GAM potansiyeli ile birlikte klasik MD benzetimleri kullanılmış ve elde edilen sonuçların ayrıntılı bir analizi sunulmuştur. Germe oranı ve boyut parametrelerinin $\gamma \mathrm{CuTi}$ nanotellerinin mekanik özellikleri üzerine etkisi, germe deformasyonu boyunca sistemin enerji değişimi ile ilişkilendirilmiştir. Öne çıkan sonuçlar aşağıda sıralanmıştır:

1. Germe oranı etkisi: yüksek germe oranları için, momentum kaynaklı bozukluklardan dolayı zayıflamış olan kristal yapılarda PE artışına bağlı olarak akma ve maksimum gerilim değerleri de artmaktadır. Germe oranındaki artışla nanotel daha erken plastik bölgeye geçmekte ve daha az plastik deformasyona uğramaktadır. Bunun sonucu olarak nanotel daha az esneyip çok daha erken kırılmaktadır. Ayrıca, lineer fit eğrisinden ortaya çıkan tutarsızlıklar göz ardı edildiğinde, Elastisite Modülü 'nün germe oranından bağımsız olduğu izlenmiştir.

2. Boyut etkisi: Bozuk bağ yapısına sahip ve komşu atomları eksik olan yüzey atomlarının daha küçük boyutlu nanotellerde etkin bir role sahip olduğu gözlenmiştir. Büyük boyutlu nanoteller ise dislokasyonların hareketi nedeniyle daha az istatistiksel salınım genliğine sahiptirler. Ayrıca, daha yüksek PE, başlangıç gerilimine ve yüzey gerilimine sahip olan ince nanotellerin daha yüksek akma ve maksimum gerilim değerlerine sahip olduğu görülmüştür. Nanotellerdeki boyut artışı ile birlikte başlangıç gerilimi, akma gerinimi ve gerilimi ve Elastisite Modülü değerlerinin aşamalı bir şekilde artarak bulk sınır değerlerine doğru yaklaştığ 1 gözlenmiştir.

MD benzetimlerimizin analizlerinden çıarılan sonuç, düşük germe oran1, küçük boyutlu $\gamma \mathrm{CuTi}$ nanotellerin plastik deformasyon süresini ve esnekliğini (sünekliğini) azalttığı yönündedir. Mevcut bulgular, küçük boyutlu $\gamma \mathrm{CuTi}$ nanoteller üzerine düşük germe oranlarının malzeme mühendisliğinde istenen mekanik özelliği elde etmek için kullanılabileceğini göstermektedir.

\section{Teşekkür}

Çalışmamızda yardımlarından dolayı Sedat ŞENGÜL'e teşekkür ederiz.

\section{KAYNAKLAR}

[1] Wu B, Heidelberg A, Boland JJ. Mechanical properties of ultrahigh-strength gold nanowires. Nat Mater 2005;4:525-9. https://doi.org/10.1038/nmat1403.

[2] Geng L, Yan F, Dong C, An C. Design and Regulation of Novel MnFe2O4@C Nanowires as High Performance Electrode for Supercapacitor. Nanomaterials 2019;9:777. https://doi.org/10.3390/nano9050777.

[3] Lieber CM. Nanoscale Science and Technology: Building a Big Future from Small Things. MRS Bull 2003;28:486-91. https://doi.org/10.1557/mrs2003.144.

[4] Wen X, Xie Y, Choi CL, Wan KC, Li X-Y, Yang S. Copper-Based Nanowire Materials: Templated Syntheses, Characterizations, and Applications. Langmuir $2005 ; 21: 4729-37$. https://doi.org/10.1021/la050038v.

[5] Sofiah AGN, Samykano M, Kadirgama K, Mohan RV, Lah NAC. Metallic nanowires: Mechanical properties - Theory and experiment. Appl Mater Today $2018 ; 11: 320-37$. https://doi.org/10.1016/j.apmt.2018.03.004.

[6] Iijima S, Qin LC, Hong BH, Bae SC, Youn SJ, Kim KS. Electron Microscopic Characterization of Silver Nanowire Arrays. Science (80- ) 2002;296:611a https://doi.org/10.1126/science.296.5568.611a.

[7] Hu L, Chen G. Analysis of Optical Absorption in Silicon Nanowire Arrays for Photovoltaic Applications. Nano Lett 2007;7:3249-52. https://doi.org/10.1021/n1071018b.

[8] Wang S, Shan Z, Huang H. The Mechanical Properties of Nanowires. Adv Sci 2017;4:1600332. https://doi.org/10.1002/advs.201600332.

[9] Zhu T, Li J. Ultra-strength materials. Prog Mater Sci 2010;55:710-57. https://doi.org/10.1016/j.pmatsci.2010.04.001.

[10] Liang H, Upmanyu M, Huang H. Size-dependent elasticity of nanowires: Nonlinear effects. Phys Rev. B2005;71:241403. https://doi.org/10.1103/PhysRevB.71.241403.

[11] Zhao L, Liu Y. The influence mechanism of the strain rate on the tensile behavior of copper nanowire. Sci China Technol Sci 2019;62:2014-20. https://doi.org/10.1007/s11431-019-9530-6.

[12] Chang L, Zhou C-Y, Pan X-M, He X-H. Sizedependent deformation mechanism transition in titanium nanowires under high strain rate tension. Mater. Des. 2017; 134: 320-30. https://doi.org/10.1016/j.matdes.2017.08.058.

[13] Chang L, Zhou C-Y, Wen L-L, Li J, He X-H. Molecular dynamics study of strain rate effects on 
tensile behavior of single crystal titanium nanowire. Comput Mater Sci 2017; 128 : 348-58 https://doi.org/10.1016/j.commatsci.2016.11.034.

[14] Ajori S, Parsapour H, Ansari R, Ameri A. Buckling behavior of various metallic glass nanocomposites reinforced by carbon nanotube and $\mathrm{Cu}$ nanowire: $\mathrm{A}$ molecular dynamics simulation study. Mater Res Express $2019 ; 6: 095070$.

https://doi.org/10.1088/2053-1591/ab2cfd.

[15] Nagarjuna S, Srinivas M, Balasubramanian K, Sarma DS. The alloy content and grain size dependence of flow stress in CuTi alloys. Acta Mater 1996 ; 44 : 2285 - 93. https://doi.org/10.1016/1359-6454(95)00358-4.

[16] Nagarjuna S, Srinivas M. High temperature tensile behaviour of a $\mathrm{Cu}-1.5$ wt.\% Ti alloy. Mater Sci Eng A 2002;335:89-93. https://doi.org/10.1016/S0921-5093(01)01945-1.

[17] Semboshi S, Nishida T, Numakura $H$. Microstructure and mechanical properties of $\mathrm{Cu}-$ 3at.\% $\mathrm{Ti}$ alloy aged in a hydrogen atmosphere. Mater Sci Eng A 2009 ; 517 : 105-13. https://doi.org/10.1016/j.msea.2009.03.047.

[18] Semboshi S, Takasugi T. Fabrication of highstrength and high-conductivity $\mathrm{Cu}-\mathrm{Ti}$ alloy wire by aging in a hydrogen atmosphere. J Alloys Compd 2013;580:S397-400. https://doi.org/10.1016/j.jallcom.2013.03.216.

[19] Li Y, Ma X-J, Liu Q-J, Liu F-S, Ma H-X, Kong G$X$, et al. First-principles calculations of the structural, elastic and thermodynamic properties of tetragonal copper-titanium intermetallic compounds. J Alloys Compd 2016;687:984-9. https://doi.org/10.1016/j.jallcom.2016.06.186.

[20] Chen S, Duan Y-H, Huang B, Hu W-C. Structural properties, phase stability, elastic properties and electronic structures of $\mathrm{Cu}-\mathrm{Ti}$ intermetallics. Philos Mag 2015;95:3535-53. https://doi.org/10.1080/14786435.2015.1091110.

[21] Vauth S, Mayr SG. Atomic dynamics in molecular dynamics simulations of glassy CuTi thin films. Appl Phys Lett 2005;86:061913. https://doi.org/10.1063/1.1861982.

[22] Dalgic SSS, Celtek M. Glass forming ability and crystallization of $\mathrm{CuTi}$ intermetallic alloy by molecular dynamics simulation. J Optoelectron Adv Mater 2011;13:1563-9.

[23] Rogachev SA, Politano O, Baras F, Rogachev AS. Explosive crystallization in amorphous CuTi thin films: a molecular dynamics study. J Non Cryst Solids 2019;505:202-10.

https://doi.org/10.1016/j.jnoncrysol.2018.10.040.

[24] Ferreira A, Borges J, Lopes C, Martin N, LancerosMendez S, Vaz F. Piezoresistive response of nanoarchitectured $\mathrm{Ti} \mathrm{x} \mathrm{Cu}$ y thin films for sensor applications. Sensors Actuators A Phys 2016;247:105-14. https://doi.org/10.1016/j.sna.2016.05.033.

[25] Kim YK, Pouraliakbar H, Hong SI. Effect of interfacial intermetallic compounds evolution on the mechanical response and fracture of layered $\mathrm{Ti} / \mathrm{Cu} / \mathrm{Ti}$ clad materials. Mater Sci Eng A
2020;772:138802

https://doi.org/10.1016/j.msea.2019.138802.

[26] Domekeli U. A molecular dynamic study of the effects of high pressure on the structure formation of liquid metallic $\mathrm{Ti}_{62} \mathrm{Cu}_{38}$ alloy during rapid solidification. Comput Mater Sci 2021;187:110089. https://doi.org/10.1016/j.commatsci.2020.110089.

[27] Plimpton S. Fast Parallel Algorithms for ShortRange Molecular Dynamics. J Comput Phys 1995;117:1-19. https://doi.org/https://doi.org/10.1006/jcph.1995.10 39.

[28] Çeltek M, Şengül S. Effects of cooling rate on the atomic structure and glass formation process of Co90Zr10 metallic glass investigated by molecular dynamics simulations. Turkish J Phys 2019;43:1125. https://doi.org/10.3906/fiz-1802-26.

[29] Çeltek M, Şengül S, Dömekeli Ü. Hızlı Soğutma Sürecinde Dörtlü Zr48Cu36Ag8Al8 İri Hacimli Metalik Camının Atomik Yapısının Gelişimi. Süleyman Demirel Üniversitesi Fen Bilim Enstitüsü Derg 2019;23:954-62. https://doi.org/10.19113/sdufenbed.566570.

[30] Celtek M. The effect of atomic concentration on the structural evolution of $\mathrm{Zr} 100-\mathrm{xCox}$ alloys during rapid solidification process. J Non Cryst Solids 2019;513:84-96. https://doi.org/10.1016/j.jnoncrysol.2019.03.014.

[31] Zhou XW, Johnson RA, Wadley HNG. Misfitenergy-increasing dislocations in vapor-deposited $\mathrm{CoFe} / \mathrm{NiFe}$ multilayers. Phys Rev B 2004;69:144113. https://doi.org/10.1103/PhysRevB.69.144113.

[32] Çeltek M, Dömekeli Ü, Şengül S. Moleküler Dinamik Benzetim Yöntemi ile Isıtma İşlemi Sırasında Platin Metalinin Yapısal Gelişimi ve Erime Noktası Üzerine Atomlar-arası Potansiyel Etkisinin Araştırılması. Bitlis Eren Üniversitesi Fen Bilim Derg 2019;8:413-27. https://doi.org/10.17798/bitlisfen.479447.

[33] Nosé S. A unified formulation of the constant temperature molecular dynamics methods. J Chem Phys 1984;81:511-9.

https://doi.org/10.1063/1.447334.

[34] Thompson AP, Plimpton SJ, Mattson W. General formulation of pressure and stress tensor for arbitrary many-body interaction potentials under periodic boundary conditions. J Chem Phys 2009;131:154107. https://doi.org/10.1063/1.3245303.

[35] Eremenko VN, Buyanov YI, Prima SB. Phase diagram of the system titanium-copper. Sov Powder Metall Met Ceram 1966;5:494-502. https://doi.org/10.1007/BF00775543.

[36] Kim YC, Bae DH, Kim WT, Kim DH. Glass forming ability and crystallization behavior of $\mathrm{Ti}$ based amorphous alloys with high specific strength. J Non Cryst Solids 2003;325:242-50. https://doi.org/10.1016/S0022-3093(03)00327-2.

[37] Kleppa OJ, Watanabe S. Thermochemistry of alloys of transition metals: Part III. Copper-Silver, Titanium, Zirconium, and -Hafnium at $1373 \mathrm{~K}$. Metall Trans B 1982;13:391-401. 
https://doi.org/10.1007/BF02667755.

[38] Guder V, Sengul S. Tensile strength and failure mechanism of hcp zirconium nanowires: Effect of diameter, temperature and strain rate. Comput Mater Sci 2020;177:109551. https://doi.org/10.1016/j.commatsci.2020.109551.

[39] Nysten B, Fretigny C, Cuenot S. Elastic modulus of nanomaterials: resonant contact-AFM measurement and reduced-size effects (Invited Paper). In: Geer RE, Meyendorf N, Baaklini GY, Michel B, editors. Testing, Reliab. Appl. Micro- Nano-Material Syst. III, 2005, p. 78. https://doi.org/10.1117/12.604981.

[40] Jing GY, Duan HL, Sun XM, Zhang ZS, Xu J, Li YD, et al. Surface effects on elastic properties of silver nanowires: Contact atomic-force microscopy. Phys Rev B 2006;73:235409. https://doi.org/10.1103/PhysRevB.73.235409.

[41] Nilsson SG, Borrisé X, Montelius L. Size effect on Young's modulus of thin chromium cantilevers. Appl Phys Lett 2004;85:3555-7. https://doi.org/10.1063/1.1807945.

[42] Li X, Ono T, Wang Y, Esashi M. Ultrathin singlecrystalline-silicon cantilever resonators: Fabrication technology and significant specimen size effect on Young's modulus. Appl Phys Lett 2003;83:3081-3. https://doi.org/10.1063/1.1618369.

[43] Nam C-Y, Jaroenapibal P, Tham D, Luzzi DE, Evoy S, Fischer JE. Diameter-Dependent Electromechanical Properties of GaN Nanowires. Nano Lett 2006;6:153-8. https://doi.org/10.1021/nl051860m.

[44] Liu KH, Wang WL, Xu Z, Liao L, Bai XD, Wang EG. In situ probing mechanical properties of individual tungsten oxide nanowires directly grown on tungsten tips inside transmission electron microscope. Appl Phys Lett 2006;89:221908. https://doi.org/10.1063/1.2397547.

[45] Liang W, Zhou M. Size and Strain Rate Effects in Tensile Deformation of $\mathrm{Cu}$ Nanowires. 2003 Nanotechnol. Conf. Trade Show - Nanotech, vol. 2, 2003, p. 452-5. https://doi.org/10.2514/6.20031612.

[46] Sainath G, Choudhary BK, Jayakumar T. Molecular dynamics simulation studies on the size dependent tensile deformation and fracture behaviour of body centred cubic iron nanowires. Comput Mater Sci 2015;104:76-83. https://doi.org/10.1016/j.commatsci.2015.03.053.

[47] Diao J, Gall K, Dunn ML, Zimmerman JA. Atomistic simulations of the yielding of gold nanowires. Acta Mater 2006;54:643-53. https://doi.org/10.1016/j.actamat.2005.10.008.

[48] Zhu T, Li J, Samanta A, Leach A, Gall K. Temperature and Strain-Rate Dependence of Surface Dislocation Nucleation. Phys Rev Lett 2008;100:025502. https://doi.org/10.1103/PhysRevLett.100.025502.

[49] Jennings AT, Weinberger CR, Lee S-W, Aitken $\mathrm{ZH}$, Meza L, Greer JR. Modeling dislocation nucleation strengths in pristine metallic nanowires under experimental conditions. Acta Mater 2013;61:2244-59.

https://doi.org/10.1016/j.actamat.2012.12.044.
[50] Weertman JR. Hall-Petch strengthening in nanocrystalline metals. Mater Sci Eng A 1993;166:161-7. https://doi.org/10.1016/09215093(93)90319-A.

[51] Chokshi AH, Rosen A, Karch J, Gleiter H. On the validity of the hall-petch relationship in nanocrystalline materials. Scr Metall 1989;23:1679-83. https://doi.org/10.1016/00369748(89)90342-6.

[52] Hall EO. The Deformation and Ageing of Mild Steel: II Characteristics of the Lüders Deformation. Proc Phys Soc Sect B 1951;64:742-7. https://doi.org/10.1088/0370-1301/64/9/302.

[53] Gupta SK, McEwan A, Lukačević I. Elasticity of DNA nanowires. Phys Lett A 2016;380:207-10. https://doi.org/10.1016/j.physleta.2015.09.038.

[54] Sarkar J, Das DK. Study of the effect of varying core diameter, shell thickness and strain velocity on the tensile properties of single crystals of $\mathrm{Cu}-\mathrm{Ag}$ core-shell nanowire using molecular dynamics simulations. J Nanoparticle Res 2018;20:9. https://doi.org/10.1007/s11051-017-4117-y. 